Journal Club

Editor's Note: These short, critical reviews of recent papers in the Journal, written exclusively by graduate students or postdoctoral fellows, are intended to summarize the important findings of the paper and provide additional insight and commentary. For more information on the format and purpose of the Journal Club, please see http://www.jneurosci.org/misc/ifa_features.shtml.

\title{
One Step Closer to a Functional Vestibular Prosthesis
}

\author{
Chris J. Dakin, L. Caitlin Elmore, and Ari Rosenberg \\ Department of Neuroscience, Baylor College of Medicine, Houston, Texas 77030 \\ Review of Lewis et al.
}

To create a stable representation of the visual scene, the brain relies on information provided by the vestibular and proprioceptive systems. Two well studied examples of this are the vestibularocular reflex, which counter-rotates the eyes during head rotation to reduce retinal image motion, and the vestibulocolic reflex, which helps stabilize the head in space (Goldberg et al., 2012). Vestibular signals not only contribute to physically maintaining the orientation of the eyes and head in space, but also influence neural representations of the visual scene. For example, the combination of visual and vestibular/proprioceptive signals underlies our perception of the visual scene as stable relative to the gravitational vector, or earthvertical, regardless of how our head is oriented in space (De Vrijer et al., 2008). This perceptual stability is closely tied to the subjective visual vertical, which is measured by having subjects align a bar with earth-vertical in darkness. Humans and monkeys generally perform this task accurately, though systematic errors attributable to an expectation of being upright occur in rolled head/body orientations (Daddaoua et al., 2008; De Vrijer et al., 2008; Lewis et al., 2008). Individuals with vestibular impairments perform poorly on this task, with

Received July 29, 2013; revised Aug. 16, 2013; accepted Aug. 16, 2013.

This work was supported by a fellowship from the Canadian Institute for Health Research (C.J.D.).

Correspondence should be addressed to Chris J. Dakin, One Baylor Plaza, MS: BCM 295, Houston, TX 77025. E-mail: dakincj@gmail.com.

DOI:10.1523/JNEUROSCI.3221-13.2013

Copyright $\odot 2013$ the authors $\quad 0270-6474 / 13 / 3314978-03 \$ 15.00 / 0$ the subjective visual vertical biased to be more inclined either to the left or to the right depending on the anatomical location of the lesion (Böhmer and Mast, 1999). Thus, in addition to the importance of vestibular/proprioceptive signals in the perception of self-motion (Gu et al., 2006), these signals serve a fundamental role in stabilizing the visual scene and contributing to our sense of verticality.

Although the perceptual contribution of vestibular signals is not always apparent, damage to the vestibular system results in a wide range of disruptive symptoms. These include vertigo, dizziness, nystagmus, and postural imbalance. In addition to traumatic or surgical causes, damage to the vestibular system can occur as a consequence of treatment with aminoglycoside drugs such as gentamicin (for bacterial infections) or other ototoxic medications. Many of these symptoms can be alleviated through compensatory adaptation of the nervous system to the vestibular deficient state; however, chronic symptoms can remain.

Recent work has sought to reduce the behavioral and perceptual consequences of chronic symptoms through the development of a vestibular prosthesis. The premise of a vestibular prosthesis is to artificially add vestibular signals through the electrical activation of vestibular nerves, much like a cochlear implant. However, limitations in the delivery of electrical stimulation are a significant impediment to the development of a vestibular prosthesis. Traditionally, electrical activation of the vestibular system was performed percutaneously. This process, called galvanic stimulation (Fitzpatrick and Day, 2004), involves placing electrodes on the skin behind the ears to modulate the firing rate of vestibular afferents traveling through the vestibulocochlear nerves (Ezure et al., 1983; Fitzpatrick and Day, 2004). Because the afferent fibers of both the otoliths (which are sensitive to linear motion) and the semicircular canals (which are sensitive to angular motion) are within close proximity in the vestibulocochlear nerve, galvanic stimulation exhibits a serious limitation: a lack of specificity. This makes it nearly impossible to electrically stimulate the vestibular afferents percutaneously in a manner that accurately replicates what would occur during natural movements. An alternative approach is to use sensory substitution, in which the tongue is electrically stimulated to provide feedback about body motion (Danilov et al., 2007). Although this method appears successful in aiding postural control, it is unlikely to provide a full spectrum solution for the many symptoms of vestibular deficits. One potential way to bypass these limitations is to surgically implant stimulating electrodes directly into the vestibular organs.

Engineering electrodes to provide isolated electrical stimulation to the semicircular canals is a logical first step in developing a functional vestibular prosthesis. Each ear possesses three distinct canals, and each of these is sensitive to rotation within a single plane. For example, if you pitch your head down by $\sim 30^{\circ}$ degrees and look over your shoul- 
der (a yaw rotation), only the horizontal canals are activated (Blanks et al., 1975). Because corresponding canals in the left and right ears work antagonistically, the vestibular signals resulting from this motion could potentially be induced artificially by oppositely stimulating the nerves from the left and right horizontal canals (Ezure et al., 1983). In this way, the hope is that a vestibular prosthesis working antagonistically on each pair of semicircular canals could recreate their naturally occurring output. Based on these principals, two groups have recently developed technologies allowing direct electrical stimulation of the canals (Gong and Merfeld, 2000; Della Santina et al., 2007).

A recent study published in The Journal of Neuroscience examined the efficacy of controlling the perception of verticality through canal electrical stimulation (Lewis et al., 2013). Specifically, monkeys were trained to perform a subjective visual vertical task in which a bar was aligned with earth-vertical in darkness. During the experiment, a monkey sat upright with the head straight relative to the shoulders, and the subjective visual vertical task was performed during periods with or without electrical stimulation of the right posterior canal. When there was no stimulation of the canal, the bar was aligned close to true earth-vertical, as expected from previous results (Daddaoua et al., 2008; Lewis et al., 2008). Under natural conditions, the activity of afferents from the right posterior canal increases when the head rolls to the right, predicting that electrical stimulation of this canal would result in the perception of the head being rolled rightward. Consistent with this, electrical stimulation caused the monkeys to orient the bar obliquely in space, rolled toward the left ear (Fig. 1). Because the canal stimulation also resulted in ocular roll within the orbit, it was necessary to show that this change in the subjective visual vertical was not due to the rotation of the eyes. Importantly, the angular deviation of the subjective visual vertical measurements from true earthvertical was greater than the induced ocular roll, indicating that this was not the case. The authors also found that higher stimulation frequencies resulted in greater angular deviations of the subjective visual vertical from true earth-vertical, suggesting that higher stimulation frequencies resulted in greater perceived head roll. Together, the results of Lewis

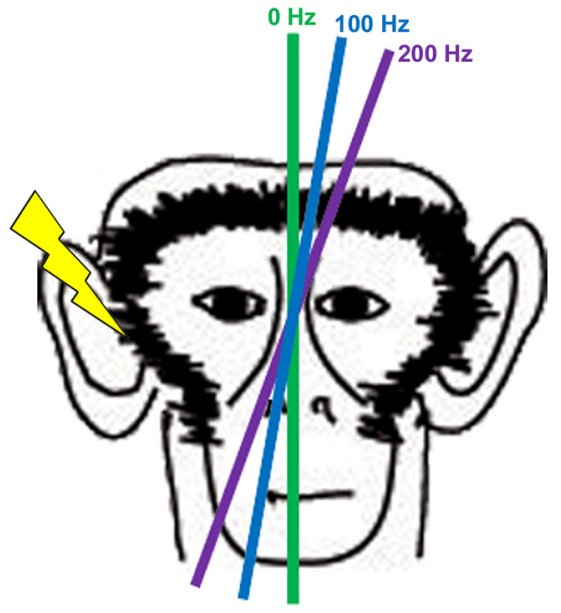

Figure 1. Electrical stimulation of the right posterior canal influences perception of the subjective visual vertical. In the absence of stimulation, the subjective visual vertical is oriented near true earth-vertical (green bar, 0 $\mathrm{Hz}$ ). Electrical stimulation of the right posterior canal (indicated by the yellow lightning bolt) results in a leftward rotation of the subjective visual vertical, consistent with the head being perceived as rolled to the right. Increasingly higher stimulation frequencies result in greater rotation from true earth-vertical (blue bar, $100 \mathrm{~Hz}$; purple bar, $200 \mathrm{~Hz}$ ).

et al. (2013) thus support previous findings that angular velocity signals contribute directly to the perception of verticality (Pavlou et al., 2003).

The aim of a vestibular prosthesis is to restore function in patients with damage to their vestibular system. Importantly, the results of Lewis et al. (2013) suggest that a vestibular prosthesis based on the direct electrical stimulation of the semicircular canals may have this effect, though this needs to be tested using animal models with experimentally induced vestibular deficits. Several significant hurdles also remain before a functional vestibular prosthesis becomes reality. One important factor is the bilaterally antagonistic relationship between vestibular organs in the left and right ears. To produce an electrically stimulated pattern of activity consistent with what occurs naturally, a vestibular prosthesis may need to include electrodes matched bilaterally as functional pairs. Additionally, engineering electrodes to provide locally specific stimulation to the otolith organs is a more difficult problem than with the canals because the motion-sensitive hair cells distributed over the surface of the otoliths vary in their directional sensitivity. Appropriate electrical stimulation of the otoliths may thus require the implantation of a multielectrode array that takes into account the hair cell direction map and that has minimal current spread (also a concern in stimulating the canals). Indeed, to be fully beneficial, a prosthesis needs to alleviate the wide array of symptoms associated with vestibular dysfunction, and this will undoubtedly require a prosthesis that acts on both the otoliths and the canals. Another consideration is the viability of a long-term surgical implant. Implanted stimulating electrodes will themselves cause some damage, and scar tissue may develop, hindering the effectiveness of the device.

Ultimately, the success of a prosthesis based on electrical stimulation of the vestibular organs may come down to a race within bioengineering. A promising parallel approach to developing prostheses has focused on growing or regenerating damaged tissue itself. For example, damaged hair cells in the mouse auditory system were recently regenerated by manipulating cellular signaling (Mizutari et al., 2013), providing hope for the future regeneration of vestibular hair cells. In the meantime, direct electrical stimulation is a promising means for replicating naturally occurring vestibular signals, and the findings of Lewis et al. (2013) move the field one step closer to a functional vestibular prosthesis.

\section{References}

Blanks RH, Curthoys IS, Markham CH (1975) Planar relationships of the semicircular canals in man. Acta Otolaryngol 80:185-196. CrossRef Medline

Böhmer A, Mast F (1999) Assessing otolith function by the subjective visual vertical. Ann N Y Acad Sci 871:221-231. CrossRef Medline

Daddaoua N, Dicke PW, Thier P (2008) The subjective visual vertical in a nonhuman primate. J Vis 8:19.1-19.8. CrossRef Medline

Danilov YP, Tyler ME, Skinner KL, Hogle RA, Bach-y-Rita P (2007) Efficacy of electrotactile vestibular substitution in patients with peripheral and central vestibular loss. J Vestib Res 17:119-130. Medline

Della Santina CC, Migliaccio AA, Patel AH (2007) A multichannel semicircular canal neural prosthesis using electrical stimulation to restore 3 -d vestibular sensation. IEEE Trans Biomed Eng 54:1016-1030. CrossRef Medline

De Vrijer M, Medendorp WP, Van Gisbergen JA (2008) Shared computational mechanism for tilt compensation accounts for biased verticality percepts in motion and pattern vision. J Neurophysiol 99:915-930. CrossRef Medline

Ezure K, Cohen MS, Wilson VJ (1983) Response of cat semicircular canal afferents to sinusoidal polarizing currents: implications for input-output properties of second-order neurons. J Neurophysiol 49:639-648. Medline 
Fitzpatrick RC, Day BL (2004) Probing the human vestibular system with galvanic stimulation. J Appl Physiol 96:2301-2316. CrossRef Medline

Goldberg JM, Wilson VJ, Cullen KE, Angelaki DE, Broussard DM, Büttner-Ennever JA, Fukushima K, Minor LB (2012) The vestibular system: a sixth sense. New York: Oxford UP.

Gong W, Merfeld DM (2000) Prototype neural semicircular canal prosthesis using patterned electrical stimulation. Ann Biomed Eng 28: 572-581. CrossRef Medline
Gu Y, Watkins PV, Angelaki DE, DeAngelis GC (2006) Visual and nonvisual contributions to three-dimensional heading selectivity in the medial superior temporal area. J Neurosci 26:73-85. CrossRef Medline

Lewis RF, Haburcakova C, Merfeld DM (2008) Roll tilt psychophysics in rhesus monkeys during vestibular and visual stimulation. J Neurophysiol 100:140-153. CrossRef Medline

Lewis RF, Haburcakova C, Gong W, Lee D, Merfeld D (2013) Electrical stimulation of semicircular canal afferents affects the per- ception of head orientation. J Neurosci 33: 9530-9535. CrossRef Medline

Mizutari K, Fujioka M, Hosoya M, Bramhall N, Okano HJ, Okano H, Edge AS (2013) Notch inhibition induces cochlear hair cell regeneration and recovery of hearing after acoustic trauma. Neuron 77:58-69. CrossRef Medline

Pavlou M, Wijnberg N, Faldon ME, Bronstein AM (2003) Effect of semicircular canal stimulation on the perception of the visual vertical. J Neurophysiol 90:622630. CrossRef Medline 